\title{
PREDICTION OF DUCTILE CRACK GROWTH IN A NARROW GAP INCONEL DISSIMILAR WELD
}

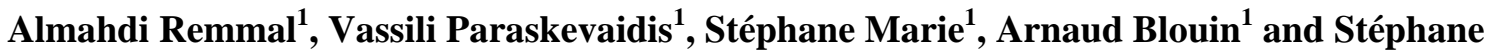 Chapuliot $^{1}$}

${ }^{1}$ Research \& Development Engineer, Mechanics \& Material, AREVA-NP, France

\begin{abstract}
In this paper, the behavior of large ductile crack propagation in a pipe using the local approach models of Gurson is predicted.

The mock-up presents a narrow gap INCONEL dissimilar weld joining a low alloy ferritic steel pipe and a 316L type stainless austenitic steel pipe. It was performed in the frame of the European Commission (EC) funded STYLE project (2010-2013). During the four points bending test on the mockup, the behavior of the crack growth was highly unexpected, and was not deeply analyzed. The initial crack, located at the interface between the weld and the ferritic Heat-Affected Zone (HAZ), grew in the weld and deviated from it to finally reach the austenitic HAZ.

A local approach modeling in order to explain the crack behavior has been performed, using the Gurson-Tvergaard-Needlemann (GTN) model.

First, the characterization of the materials composing the weld is made through the experimental program of the STYLE project. Then, GTN parameters are identified using the experimental data from the laboratory specimens. The behavior of Compact Tension (CT) specimens and the pipe are then numerically predicted. It is shown that GTN model is able to catch the mechanical differences between the CT specimens and the pipe, providing a good prediction of the crack propagation during the four points bending test.
\end{abstract}

\section{INTRODUCTION}

In the frame of the EC funded STYLE project [1] dedicated to piping integrity assessment, a mock-up consisting in a narrow gap INCONEL 52 dissimilar weld (Figure 1) joining a 18 MND 5 low alloy ferritic steel pipe and a 316L type stainless austenitic steel pipe was manufactured. A circumferential crack was introduced at the interface between the INCONEL weld and the ferritic HAZ (Figure 2). The pipe is a mock-up at scale $1 / 2$ of $\mathrm{EPR}^{\mathrm{TM}}$ main coolant line.

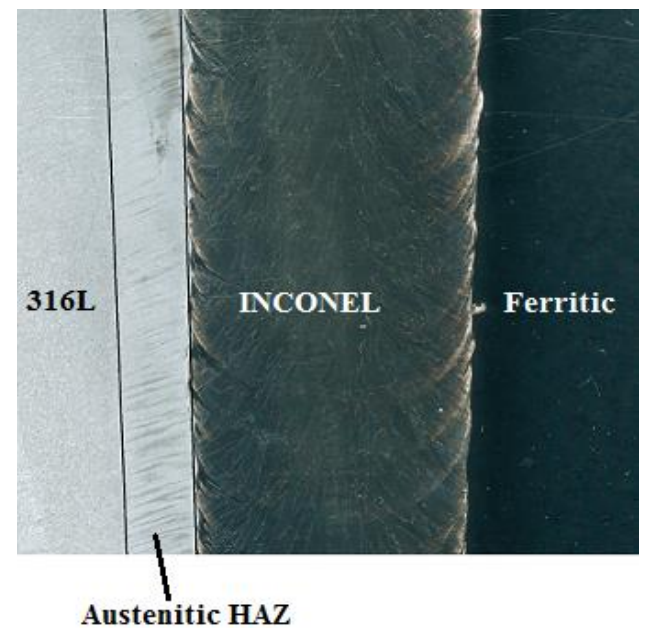

Figure 1: Narrow gap INCONEL dissimilar weld 


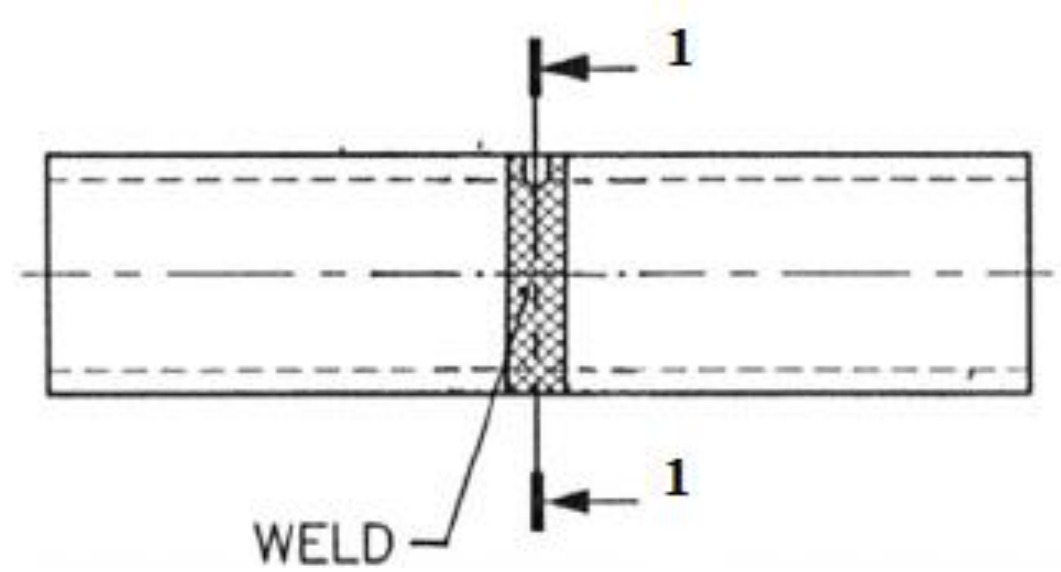

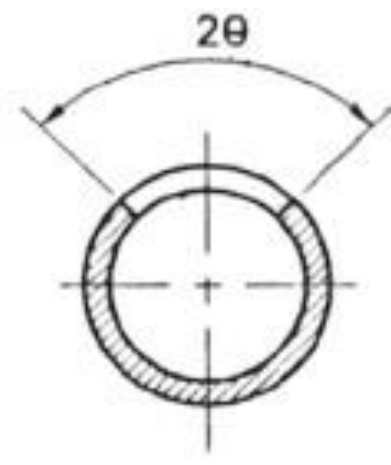

SECTION 11

Figure 2: Circumferential through wall crack at the interface between the INCONEL weld and the ferritic $\operatorname{HAZ}\left(\mathbf{2} \boldsymbol{\theta}=\mathbf{9 0}^{\circ}\right)$

During the four points bending test, the crack propagated inside the INCONEL and continued growing in the austenitic part of the mock-up as shown in Figure 3 [6]. This result was highly unexpected since the interface between the weld and the ferritic HAZ has the lowest toughness of the assembly: in the $\mathrm{CT}$ specimens the crack remained at this interface during crack propagation.
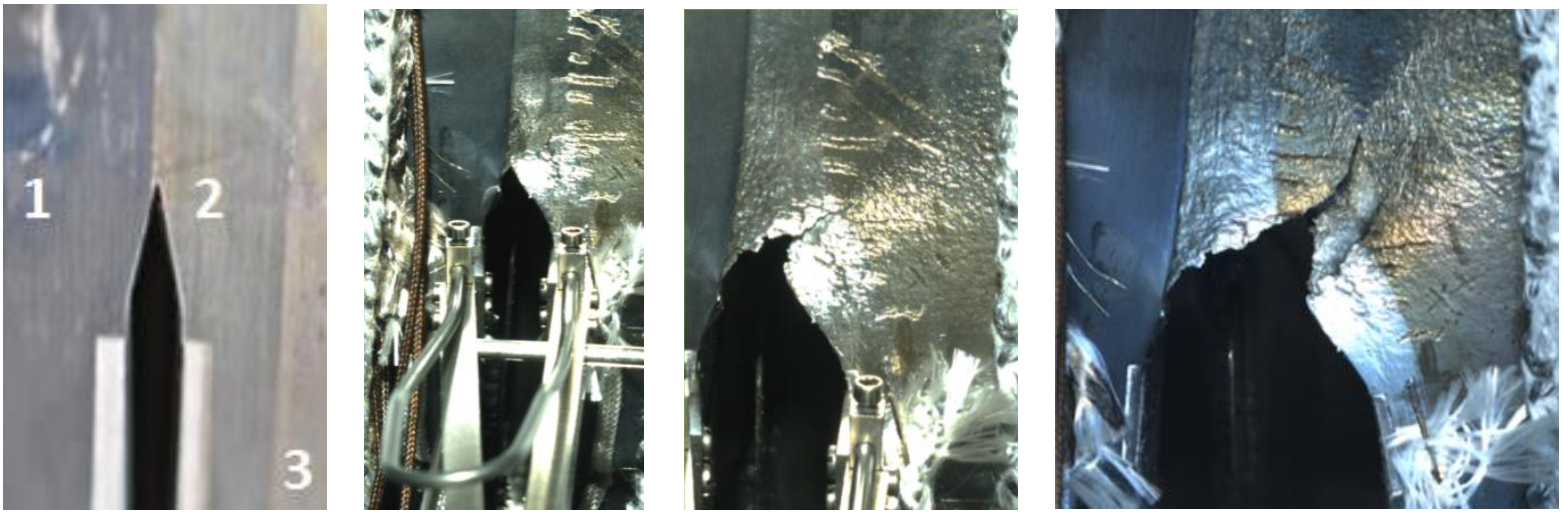

Figure 3: Crack propagation during the four points bending test (1: 18 MND 5; 2: INCONEL; 3: $316 L)$

A local approach modeling of the laboratory specimens and the pipe itself has been performed to explain this result. This paper presents a synthesis of the results, from the identification of the parameters of the Gurson-Tvergaard-Needlemann (GTN) model ([1], [2], [3]) to the prediction of the crack propagation in the mock-up.

\section{CHARACTERIZATION OF MATERIAL}

The characterization of the materials composing the mock-up was made through an experimental program performed in the frame of STYLE project [5].

Tensile tests were performed at $300^{\circ} \mathrm{C}$ on flat and cylindrical cross-weld specimens in order to determine the stress-strain constitutive law for each material in this heterogeneous mock-up.

Fracture tests were also performed on notched tensile specimens at $300^{\circ} \mathrm{C}$. For the INCONEL weld, three different sizes of the notch radius were considered: $1 \mathrm{~mm}, 2 \mathrm{~mm}$ and $4 \mathrm{~mm}$. For the stainless steel, the volume of available material allowed the use of larger specimens, so the notch radiuses were slightly different: $2 \mathrm{~mm}, 4 \mathrm{~mm}$ and $8 \mathrm{~mm}$. 
Finally, three tearing tests were performed on side grooved CT18 specimens with lateral notches. The sampling is such that the crack propagates in the INCONEL weld. A CT specimen and the localization of the associated crack plane are presented in Figure 4. The characteristics of the CT studied are presented in Table 1, where $a_{0}$ is the pre-crack length of the specimen.
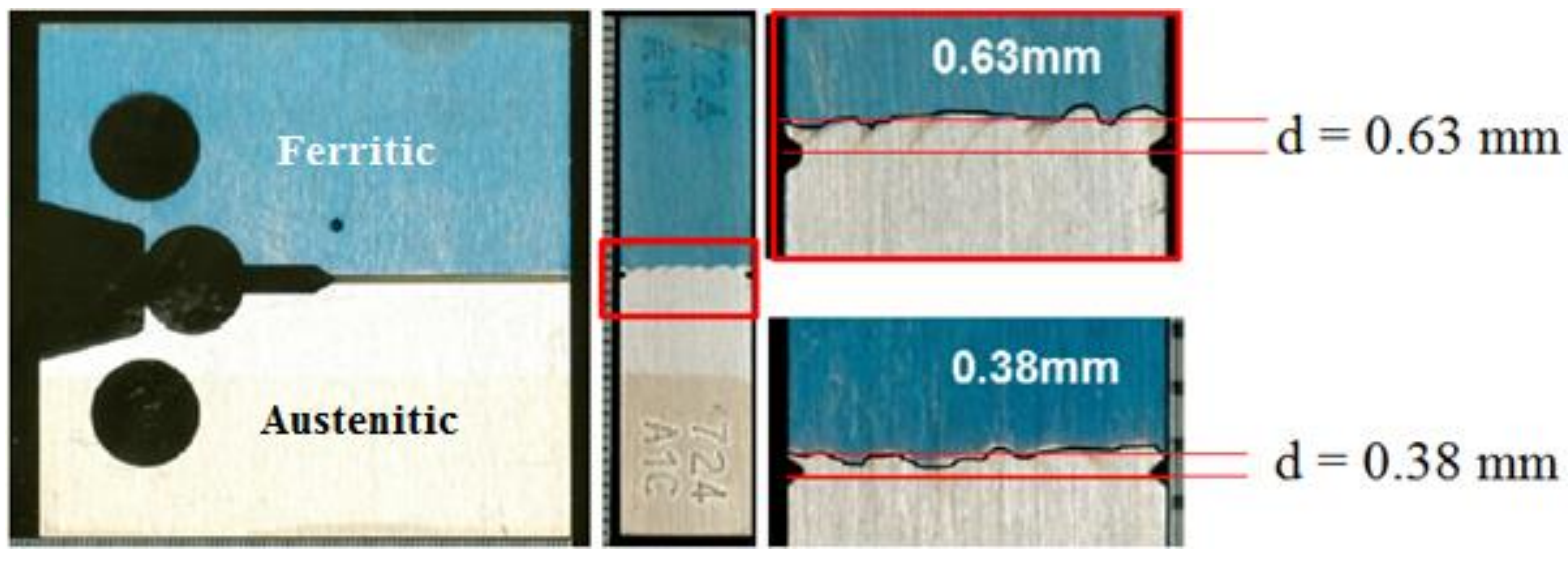

Figure 4: Crack plane localization

\begin{tabular}{|c|c|c|}
\hline CT18 & $\boldsymbol{a}_{\mathbf{0}}(\boldsymbol{m m})$ & $\boldsymbol{d}(\boldsymbol{m m})$ \\
\hline $\mathrm{A}$ & 18.93 & 0.63 \\
\hline $\mathrm{C}$ & 20.34 & 0.63 \\
\hline $\mathrm{X}$ & 19.23 & 0.38 \\
\hline
\end{tabular}

Table 1: Characteristics of CT18 A, C and X

\section{IDENTIFICATION OF THE GTN' S PARAMETERS}

\subsection{GTN's criterion}

The model used is the GTN model ([1], [2], [3]), where the damage is taken into account by considering porosity in an isotropic matrix. GTN's-criterion which takes into account the Tvergaard parameter $q$ [2], and the effective porosity $f^{*}[3]$ is:

$$
\phi\left(\Sigma_{i j}, \bar{\sigma}, f^{*}\right)=\frac{\Sigma_{e q}^{2}}{\bar{\sigma}^{2}}+2 f^{*} q \cosh \left(\frac{3 \Sigma_{m}}{2 \bar{\sigma}}\right)-1-q^{2} f^{* 2} \leq 0
$$

Where $\Sigma_{e q}$ is the Von Mises stress in the material, $\Sigma_{m}$ the stress mean part and where $f^{*}$ is a function of the porosity $f$ of the material:

$$
f^{*}=\left\{\begin{array}{cl}
f & \text { if } f \leq f_{c} \\
f_{c}+\delta\left(f-f_{c}\right) & \text { if } f>f_{c}
\end{array}\right.
$$

Where $f_{c}$ is the porosity for which the coalescence starts, and $\delta$ is a scalar factor.

\subsection{Numerical computation of notched tensile specimen tests}

In order to identify $f_{c}$ and $\delta$, simulations are performed using an axisymmetric mesh of the tensile notched specimens on SYSTUS software from ESI GROUP [SYSTUS]. 

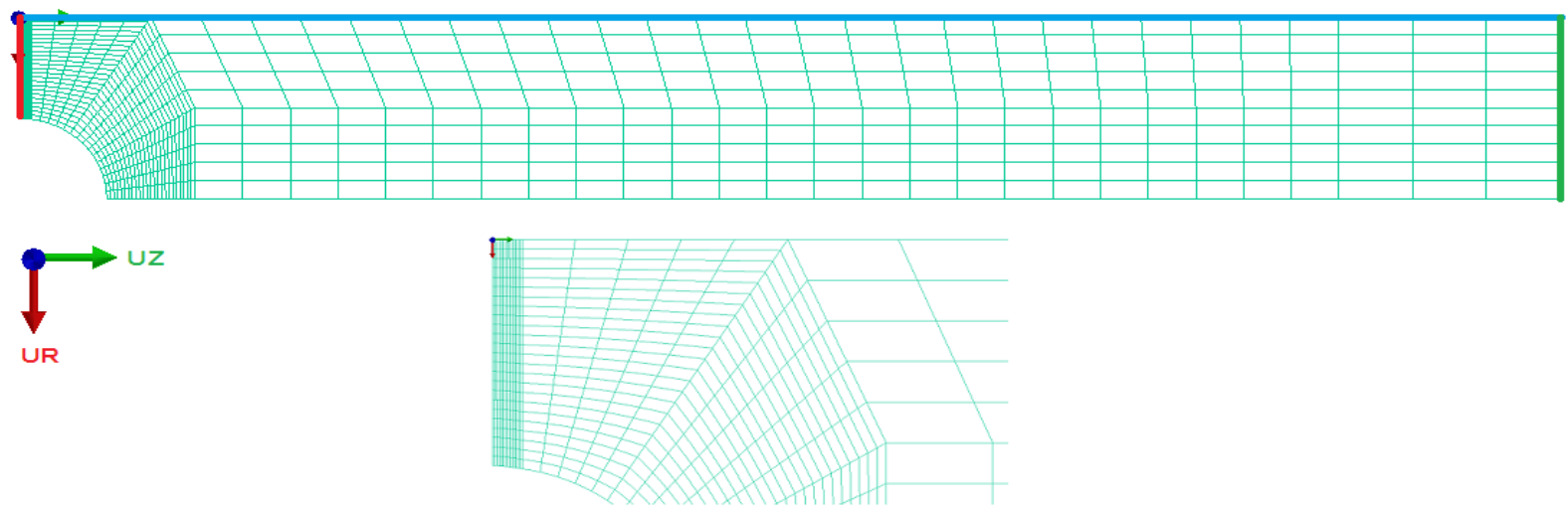

Figure 5: Axisymmetric mesh of a notched tensile specimen

The computation takes into account large displacements and strains, the boundary conditions are (Figure 5):

- Displacements of the blue line are blocked in the direction of $\vec{u}_{r}$;

- Displacements of the red line are blocked in the direction of $\vec{u}_{z}$;

- Displacements of the green line at the top of the specimen are imposed in the direction of $\vec{u}_{z}$. An initial arbitrary, but classical, porosity $f_{0}$ of $10^{-4}$ was chosen. The value of the Tvergaard parameter $q$ is classically defined equal to 1.5 .

\subsection{Identification of GTN's parameters}

The results of the calculations are presented, Figures 6 and 7, for the final sets of parameters provided in Table 2 for the INCONEL 52 nickel based alloy and the 316 stainless steel.

\begin{tabular}{|c|c|c|}
\hline & INCONEL & Stainless steel \\
\hline $\boldsymbol{f}_{\mathbf{0}}$ & $10^{-4}$ & $10^{-4}$ \\
\hline $\boldsymbol{f}_{\boldsymbol{c}}$ & $10^{-4}$ & $1.4 \cdot 10^{-4}$ \\
\hline $\boldsymbol{\delta}$ & 1.8 & 5.5 \\
\hline $\boldsymbol{q}$ & 1.5 & 1.5 \\
\hline
\end{tabular}

Table $2:$ GTN's parameters for INCONEL and Stainless steel 


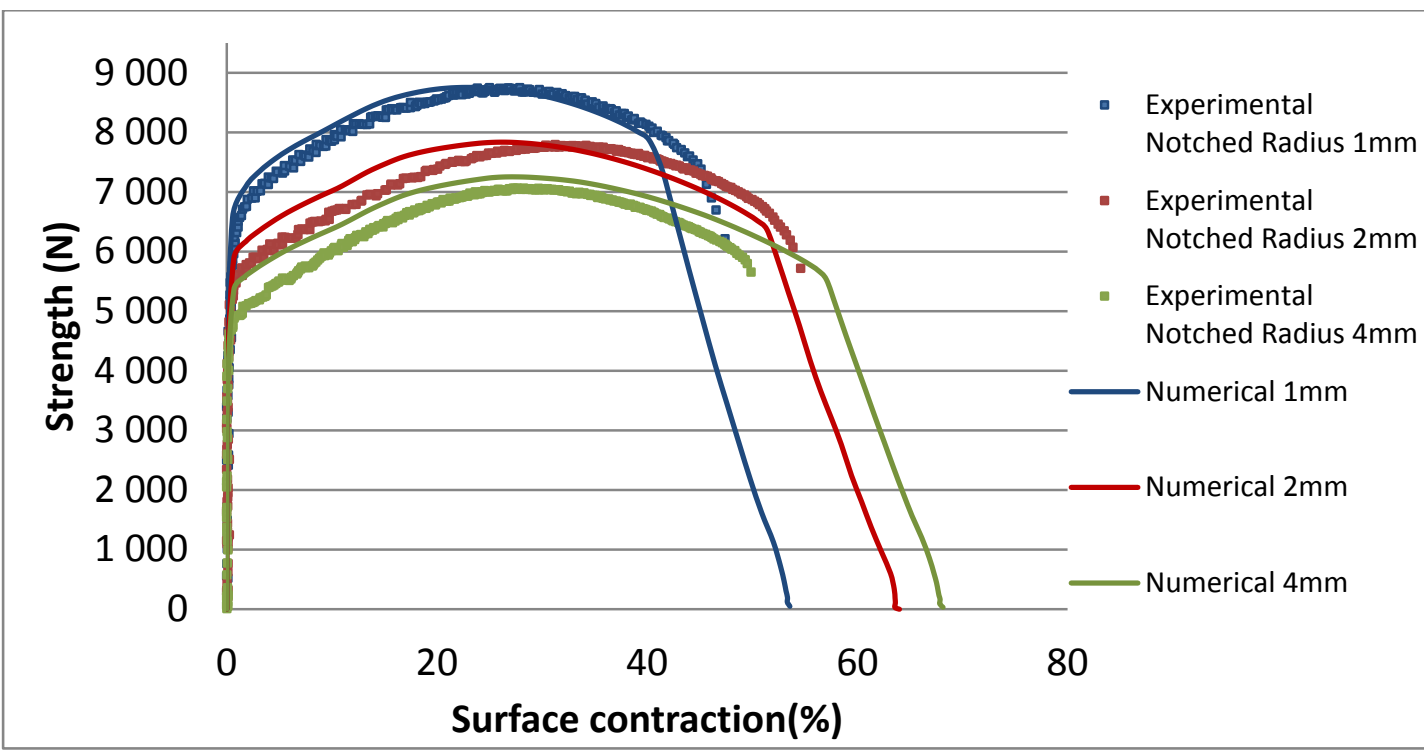

Figure 6: Strength-surface contraction curves for INCONEL notched tensile - Comparison between experimental data and numerical simulations

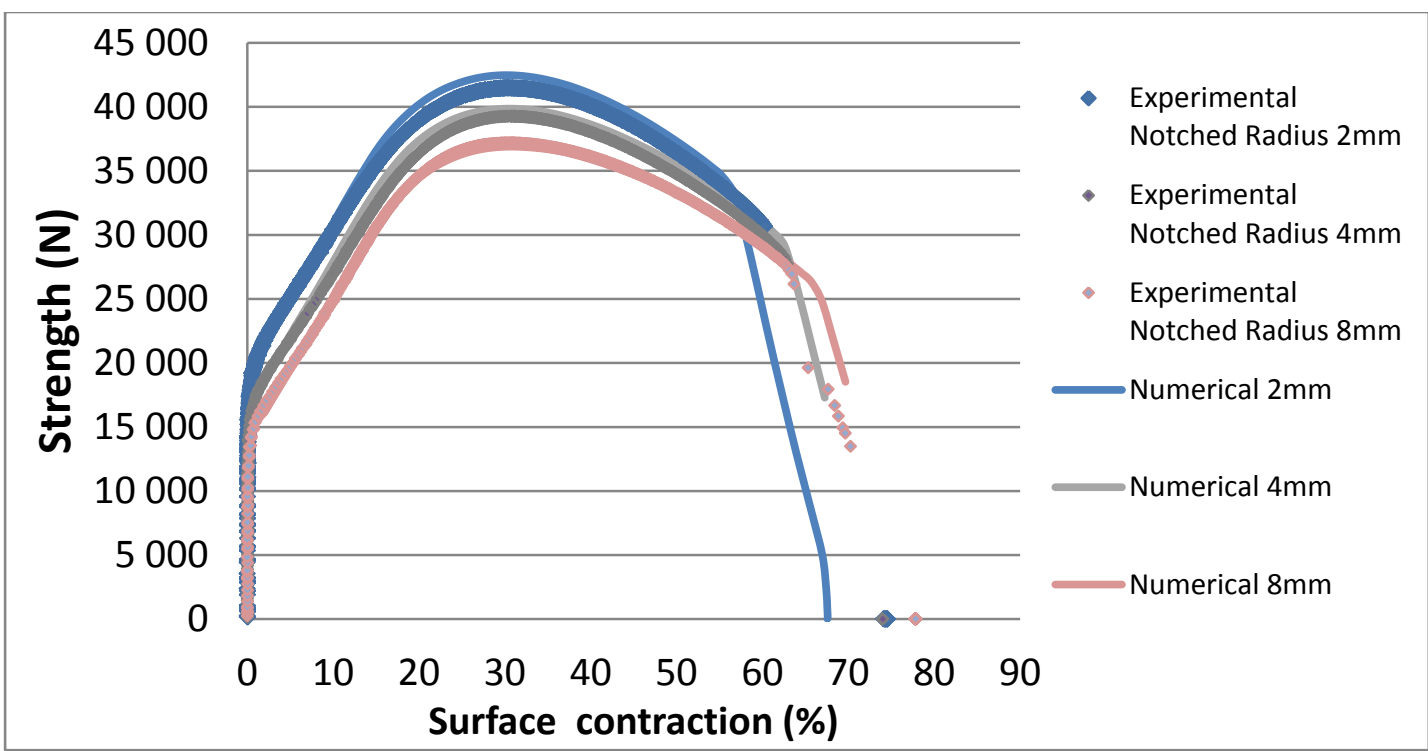

Figure 7: Strength-surface contraction curves for the 316 stainless steel notched tensile - Comparison between experimental data and numerical simulations

The sets of parameters presented here allow the prediction of the behavior of the notched tensile specimens. An important disparity between experimental data and numerical simlations is observed for the INCONEL tensile for a notched radius of $4 \mathrm{~mm}$.

A bigger fracture surface contraction is expected with a larger notched radius. However, this is not the case for the experimental curve presented in Figure 6 where the anticipated fracture is probably related to a defect in the weld. Parameters are then chosen to fit the tensile specimens with a notch radius of $1 \mathrm{~mm}$ and $2 \mathrm{~mm}$.

Without taking into consideration the 4mm INCONEL notched tensile specimen, a very good agreement is found between the simulations and the experimental results: the strength is fully restored, and the surface contraction at failure load is well reproduced. 


\section{NUMERICAL MODELIZATION OF THE CRACK GROWTH FOR CT18 SPECIMENS}

\subsection{Numerical computation of CT18 specimen tests based on a local model}

Simulations have been performed on the CT18 multi-material specimens. The mesh used is presented on Figure 8: the elements size is 200 microns in the area of interest. The mesh is constructed parametrically from the pre-crack length $a_{0}$ and the average distance between the welding and the crack $d$ and the size of the mesh in the area of interest. The GTN model is applied only on the elements close to the propagation area (of height $d$ ) as defined Figure 4. In the rest of the INCONEL material, and for other materials, a classical elastic-plastic behavior is considered.

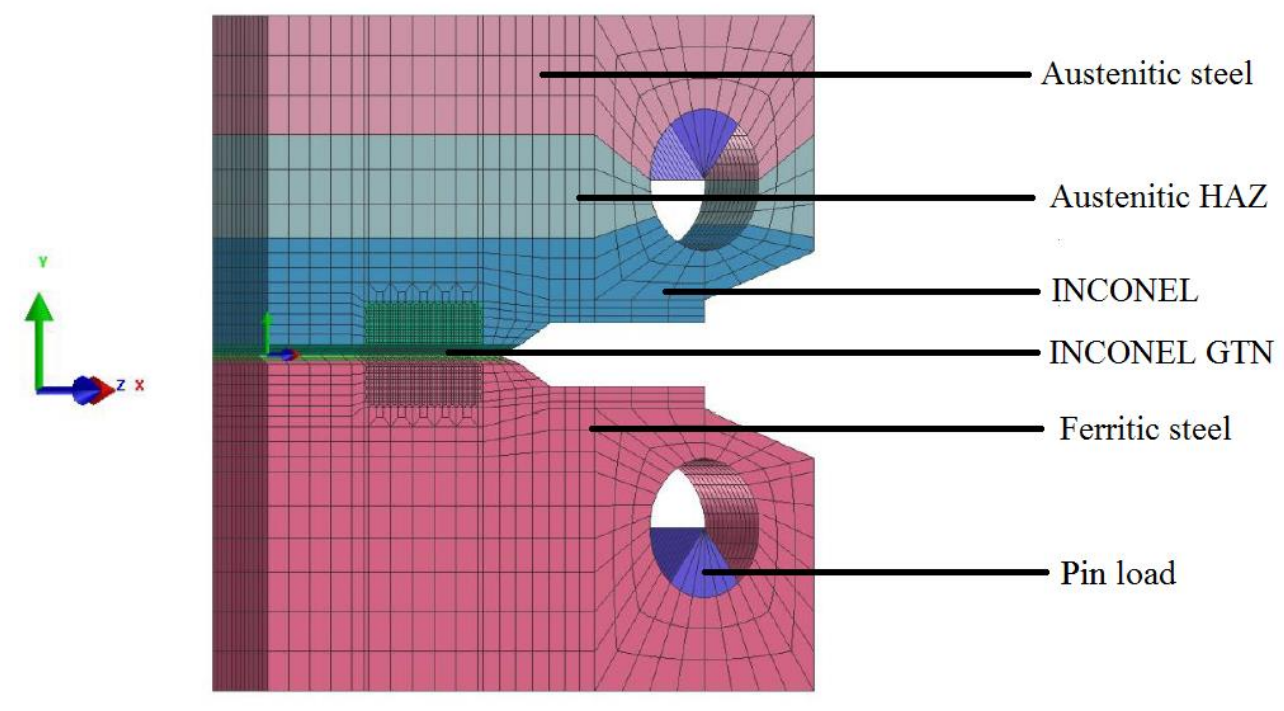

Figure 8: CT18 Mesh - 200 microns in the area of interest (INCONEL GTN)

The parameters are only identified for the INCONEL weld since no CT tests were performed with the crack in the austenitic HAZ. From the set of parameters identified on notched tensile specimens, the modeling of the $\mathrm{CT}$ allows the adjustment of the mesh size to predict the correct experimental crack growth rate. Figure 9 shows the strength-CMOD curves for different mesh sizes in the area of interest and Figure 10 presents the CMOD-crack length curve for a mesh size of 1,000 microns. A final size of $1,000 \mu \mathrm{m}$, consistent with the tests, has been retained from those results.

\subsection{Nonlocal model}

The model used in the first part of this paper is a local formulation of the GTN model which is dependent on the element-size around the crack path.

In order to prevent the result from being dependent of the mesh size, the delocalization option given by the F.E calculation software [SYSTUS] was also used. This nonlocal model is based on a heuristic proposal from Leblond et al's [4] that consists of retaining all equations of GTN's original model, except the evolution equation of the porosity which is replaced by:

$$
\frac{\boldsymbol{d}(\ln (f))}{\boldsymbol{d} t}(\boldsymbol{x})=\frac{\mathbf{1}}{\boldsymbol{A}(\boldsymbol{x})} \int_{\boldsymbol{\Omega}} \psi(\boldsymbol{x}-\boldsymbol{y})\left[\frac{d(\ln (f))}{d t}\right]^{l o c}(\boldsymbol{y}) \boldsymbol{d} \boldsymbol{V}_{\boldsymbol{y}}
$$

In this expression, $\Omega$ denotes the considered body, $\psi$ is some bell-shaped weighing function, and the factor $A$ is a normalization factor. $\left[\frac{d(\ln (f))}{d t}\right]^{l o c}$ is calculated using the local porosity rate given by the evolution law of the porosity. 


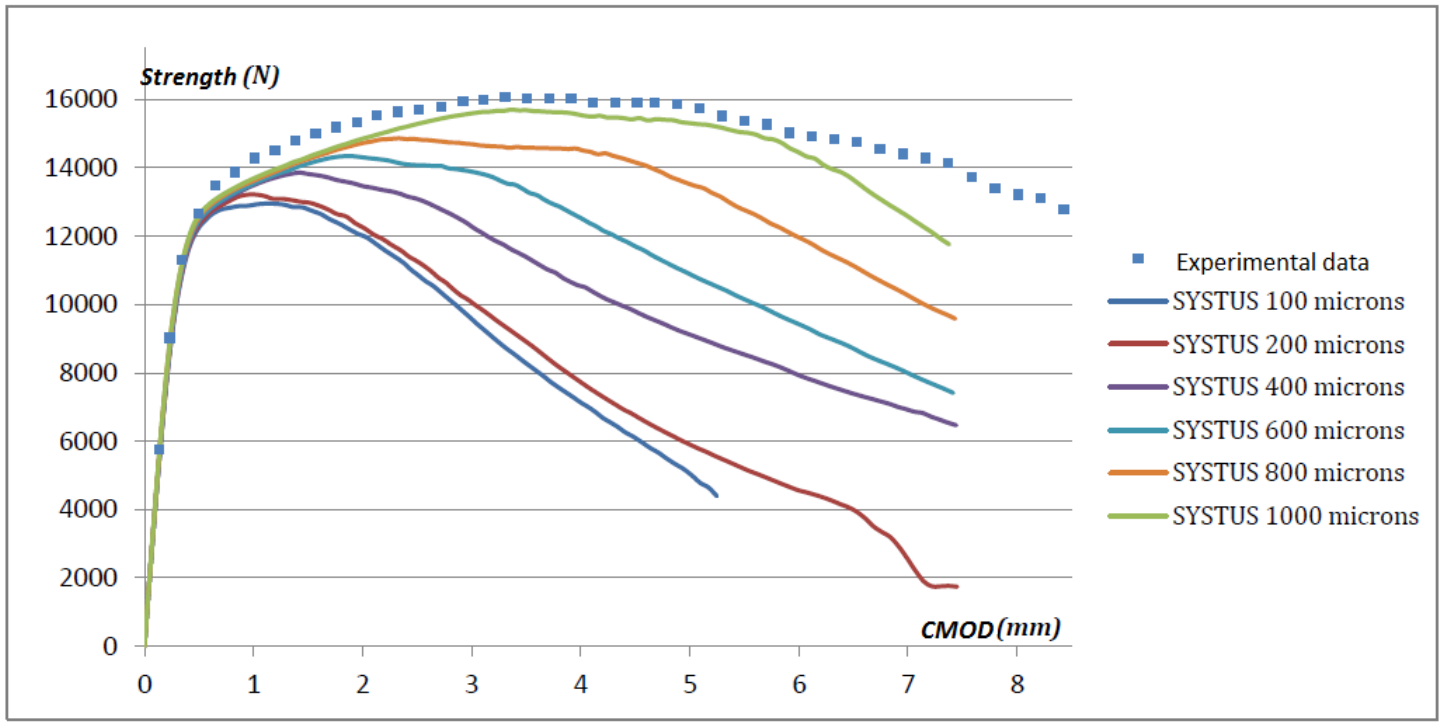

Figure 9: CT18X Strength-CMOD curves for different mesh sizes in the area of interest

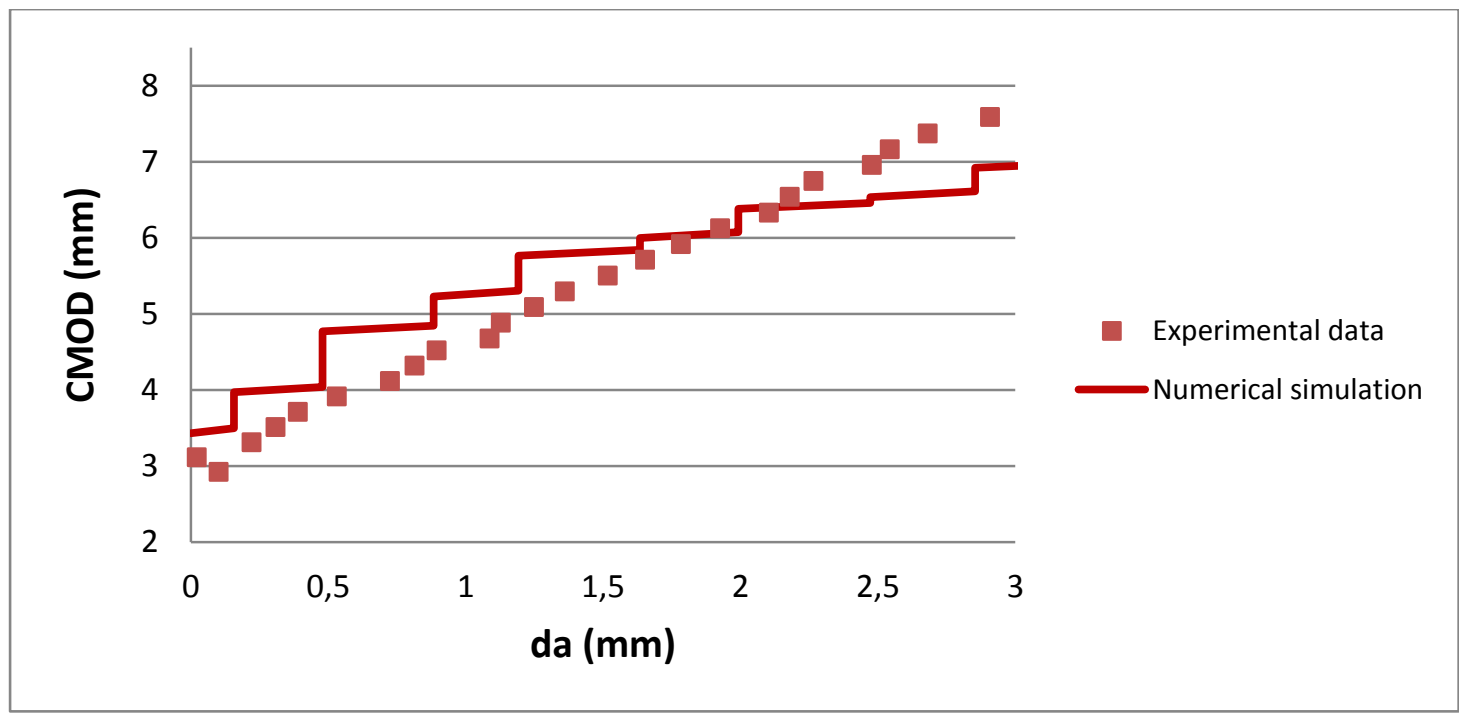

Figure 10: CT18X CMOD-crack length (da) curve for 1,000 $\mu \mathrm{m}$

In the F.E calculation software [SYSTUS], the weighing function takes the form of a Gaussian:

$$
\psi(x)=\exp \left(-\frac{|| x||^{2}}{b^{2}}\right)
$$

Where $b$ is a characteristic microstructural length. Thus, the dependence of the result on the mesh size is replaced by adding a parameter $b$ in the model. The value of $b$ have then to be specified and the result becomes dependent of the parameter $b$ and is no longer dependent on the mesh size in the area of interest under a certain value.

\subsection{Results of the simulations for the nonlocal model}

The results of the simulations using the nonlocal model for the following set of parameters are presented hereafter: 


\begin{tabular}{|c|c|c|}
\hline & INCONEL & Stainless steel \\
\hline $\boldsymbol{f}_{\mathbf{0}}$ & $10^{-4}$ & $10^{-4}$ \\
\hline $\boldsymbol{f}_{\boldsymbol{c}}$ & $10^{-4}$ & $1.4 \cdot 10^{-4}$ \\
\hline $\boldsymbol{\delta}$ & 1.8 & 5.5 \\
\hline $\boldsymbol{q}$ & 1.5 & 1.5 \\
\hline $\boldsymbol{b}$ & 0.45 & - \\
\hline
\end{tabular}

Table 3 : Set of parameters for the nonlocal model

For the INCONEL weld, the crack in the CT specimen was located at the interface between weld metal and ferritic HAZ and the propagation follows this interface. The mesh size of the area of interest is 200 microns for the nonlocal model. Figure 11 presents the strength-CMOD curve and Figure 12 the porosity in the CT specimen. Figure 13 shows the CMOD-crack length curve, and Figure 14 compares the crack surface of the simulations with the crack surface obtained during the experimental tests. From all those figures, a good agreement between experimental data and simulations is demonstrated.

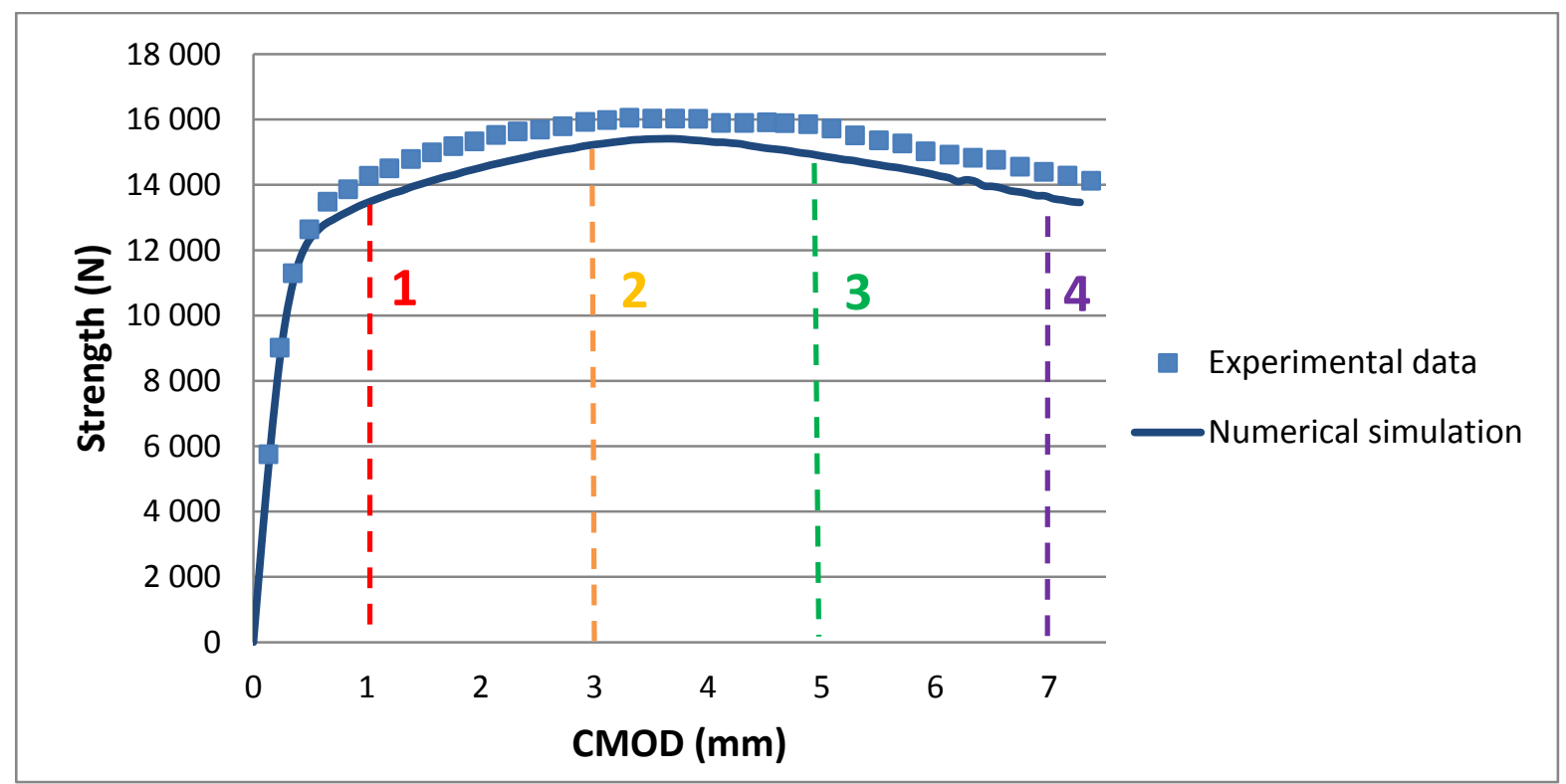

Figure 11: CT18X strength-CMOD curve 

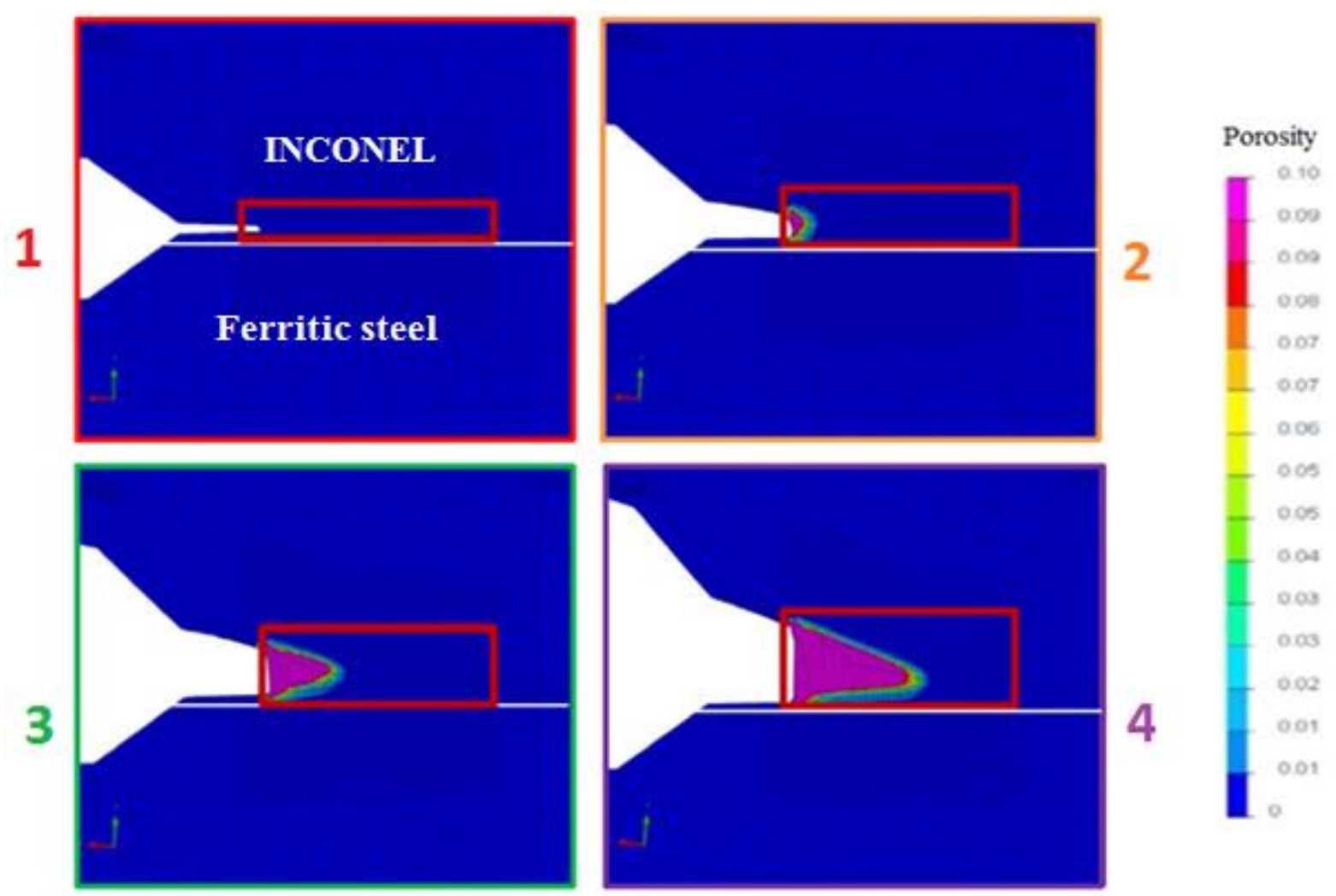

Figure 12: Numerical representation of the crack growth in the symmetry plan of the CT specimen

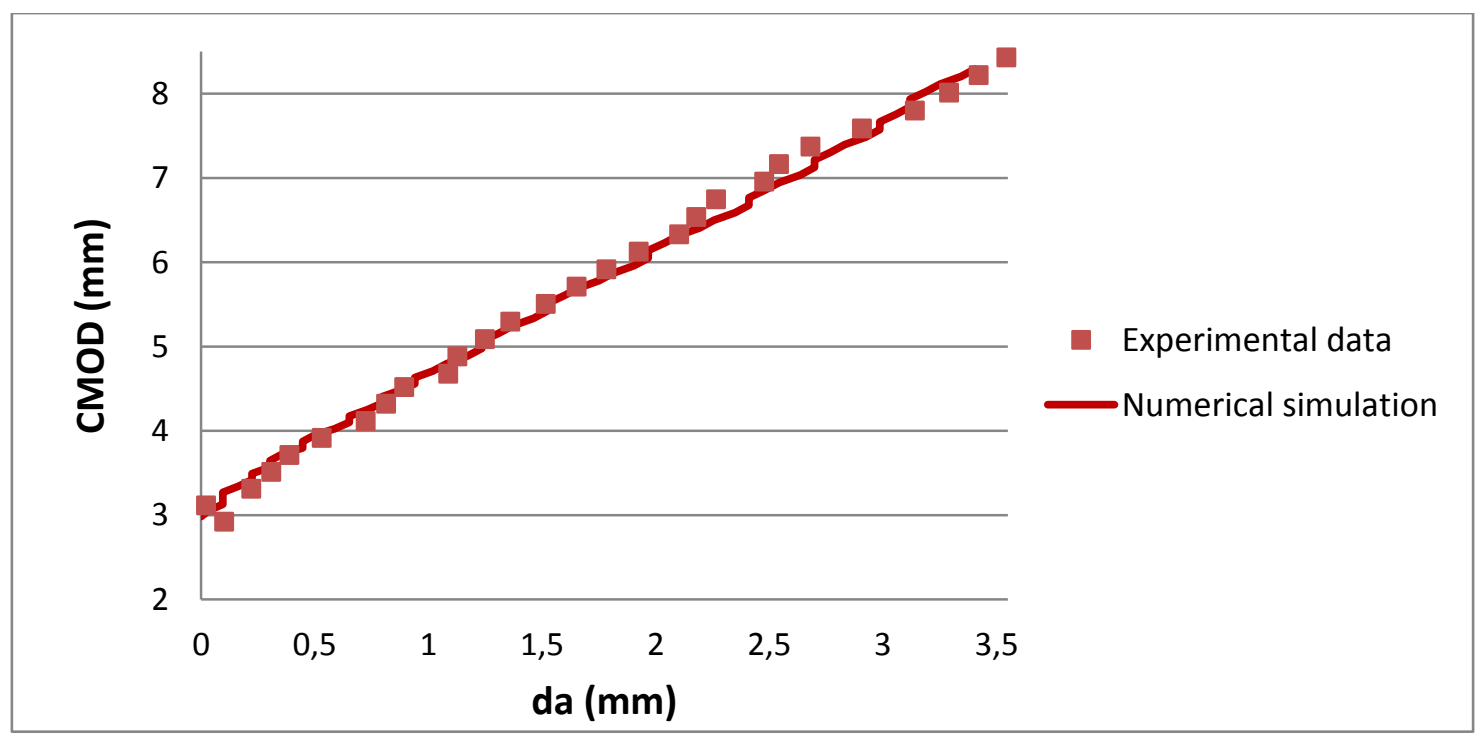

Figure 13: CT18X CMOD-crack length (da) curve 

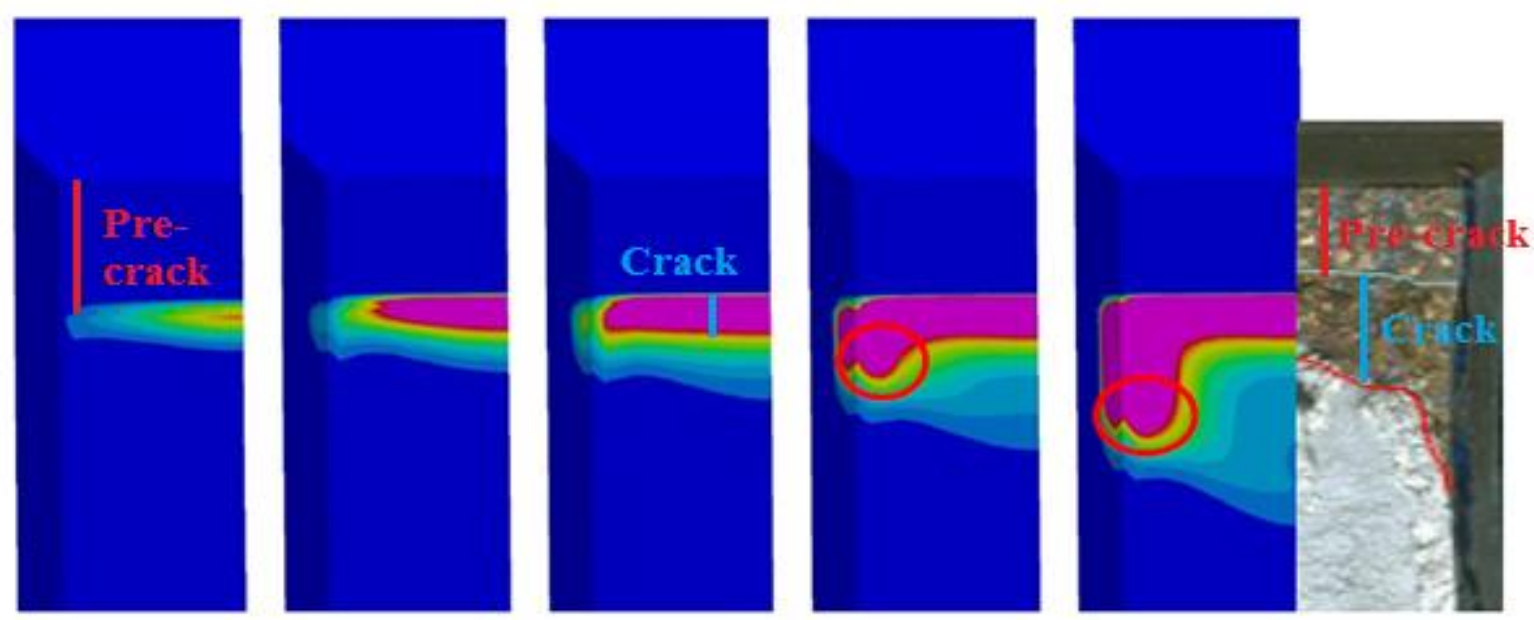

Figure 14: Comparison between the numerical representation of the crack surface and the observed one for CT18X

\section{NUMERICAL MODELIZATION OF THE BEHAVIOR OF THE MOCK-UP DURING THE FOUR POINTS BENDING TEST}

\subsection{Experimental device}

The mock-up used for the four points bending test is a pipe, at scale $1 / 2$ of $\mathrm{EPR}^{\mathrm{TM}}$ main coolant line, with an internal radius of $271 \mathrm{~mm}$ and an external radius of $352 \mathrm{~mm}$. As said in introduction, the mockup presents a narrow gap INCONEL 52 dissimilar weld joining a 18 MND 5 low alloy ferritic steel pipe and a 316L type stainless austenitic pipe. A $90^{\circ}$ circumferential through wall crack was introduced at the interface between the INCONEL weld and the ferritic HAZ.

As indicated in the introduction, during the four points bending test, the crack propagated inside the INCONEL and continued growing in the austenitic part of the mock-up (Figure 3). Figure 15 presents the experimental device for this test. The green arrow represents the loading on the two internal bending points leading to the bending of the pipe represented by the red arrows. The temperature was set to $300^{\circ} \mathrm{C}$.
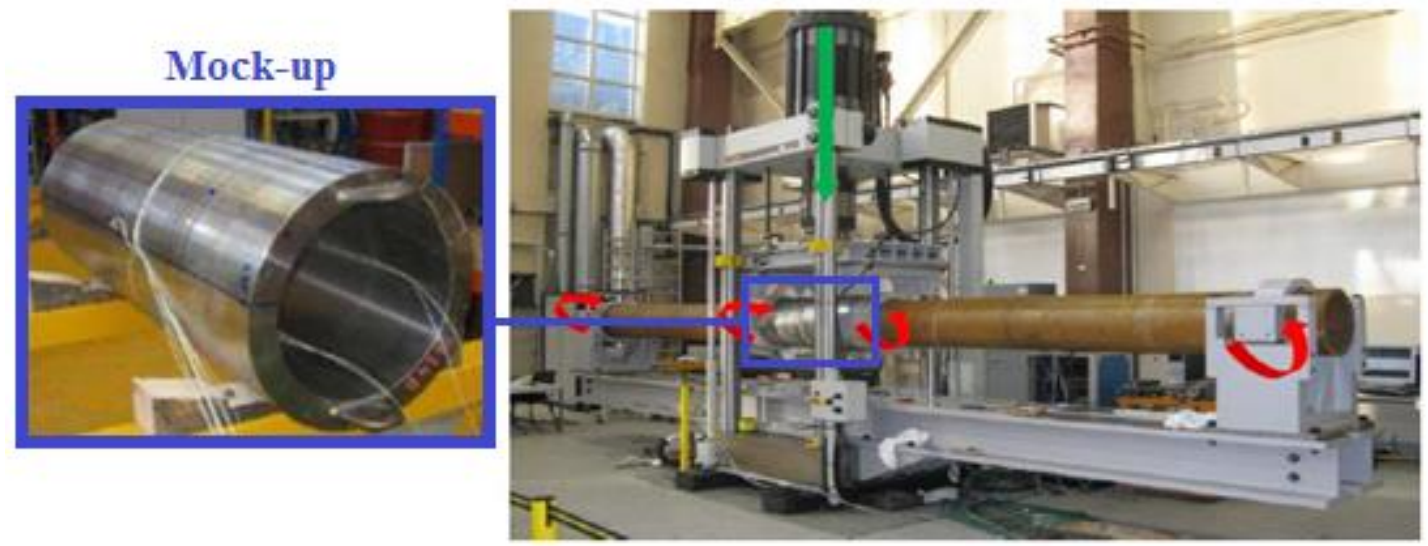

Figure 15: Presentation of the experimental device for the four points bending test [5, 6]

\subsection{Results of the simulations - First model: pure bending}

First simulations were performed under a pure bending loading in order to simulate the moment of force - CMOD curve for the mock-up. Figure 14 presents the mesh of the half pipe used and the 
boundary conditions for this first simulation. Imposed strengths are imposed on the rigid plug added to the mesh in order to simulate properly the pure bending. As mentioned above, a bifurcation of the crack (at an angle of $45^{\circ}$ ) was observed during the test. A thin "stair" zone, as shown in Figure 16, was created to set a sufficiently refined mesh in the area where the propagation may occur, with an optimized number of elements for calculation. It thus decreases the number of elements with 3136 elements less per layer of elements. Since the crack does not propagate in the ferritic steel, the fine zone is placed at the ferritic/INCONEL interface. Figure 17 presents the moment of force-CMOD curve obtained through the simulations for the parameters previously identified.

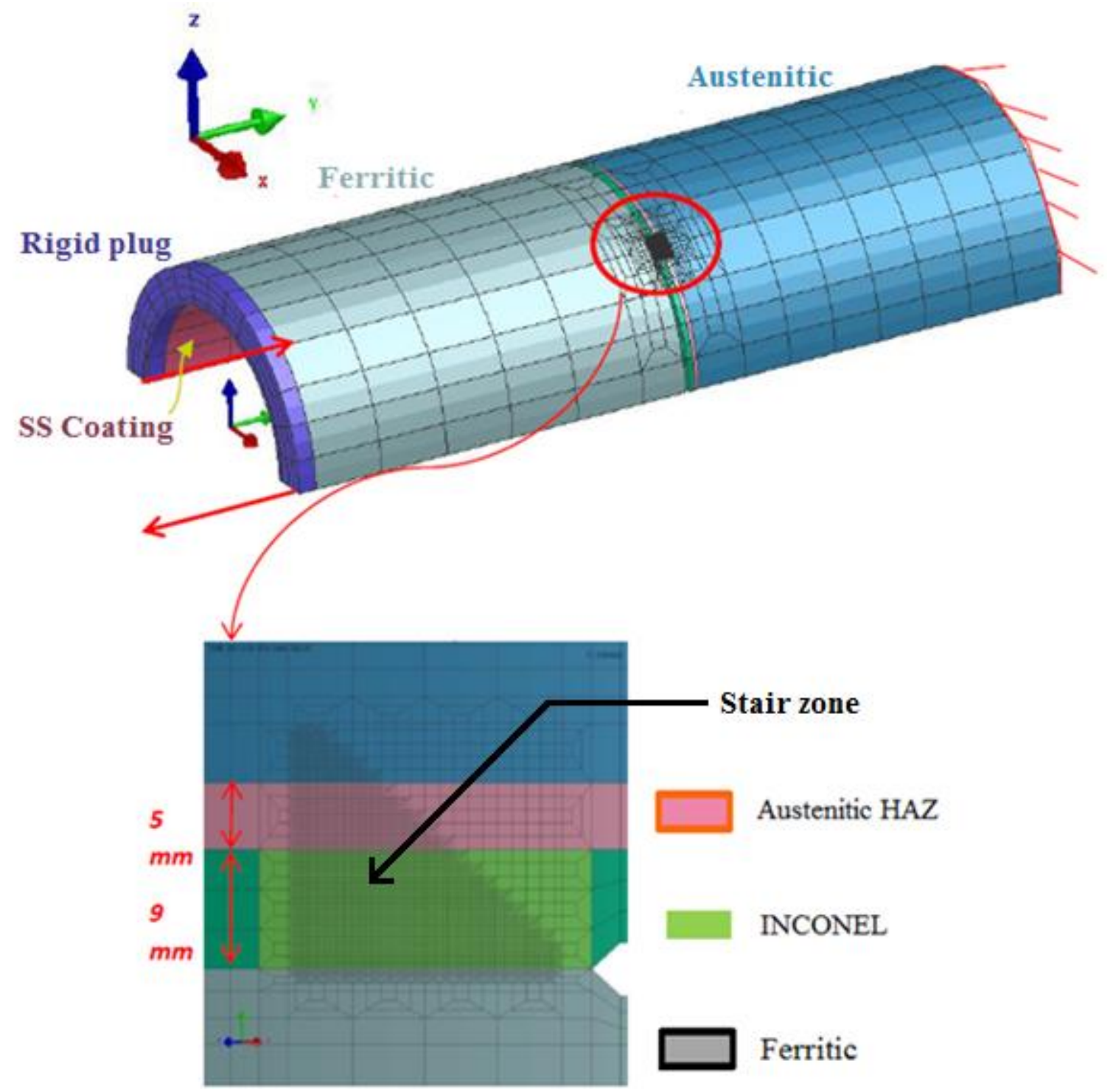

Figure 16: Mesh and boundary conditions for the pure bending test 


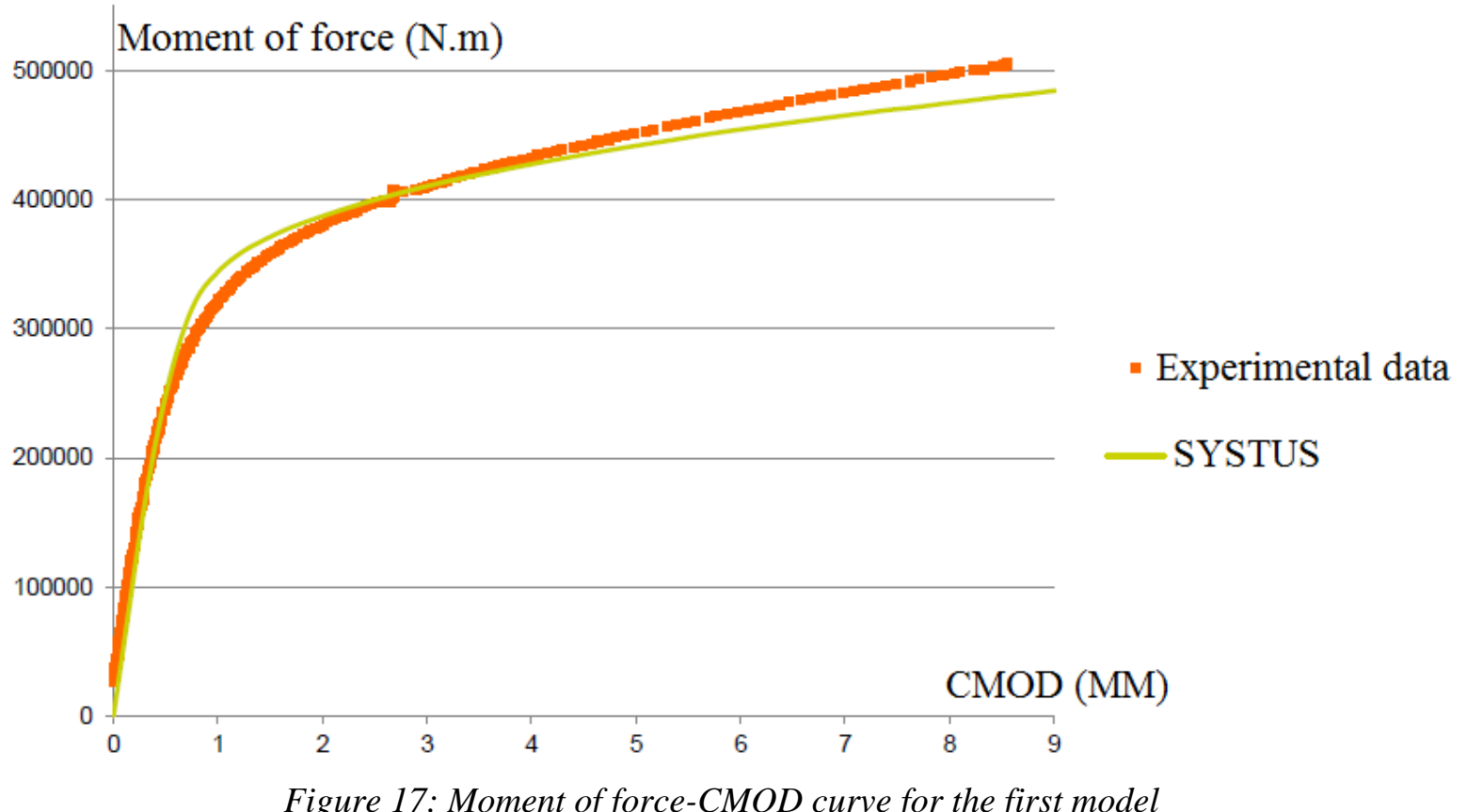

With this model, only the beginning of the four bending points test can be simulated correctly. Replacing imposed strengths with imposed displacements would allow simulating the entire mechanical test. However, it would add a traction effort that would distort the results. The only way to simulate the whole test with this kind of loadings would be to impose a rotation on the rigid plug. Since these types of boundary conditions are difficult to implement on this F.E software, the fourpoint bending test was then modeled as it has been realized experimentally.

\subsection{Results of the simulations - Second model: Four points bending}

The numerical cost of the nonlocal model is too important for this model. The simulations were then conducted only with the "local model" and a mesh size of 1,000 microns in the area of interest, as identified in section 4-1, was chosen according to the previous results. The distance between the two internal bending points can evolve from $1,000 \mathrm{~mm}$ to $1,300 \mathrm{~mm}$, and the distance between the two external bending points can reach $8,000 \mathrm{~mm}$. The mesh used for the simulations is presented Figure 18 .

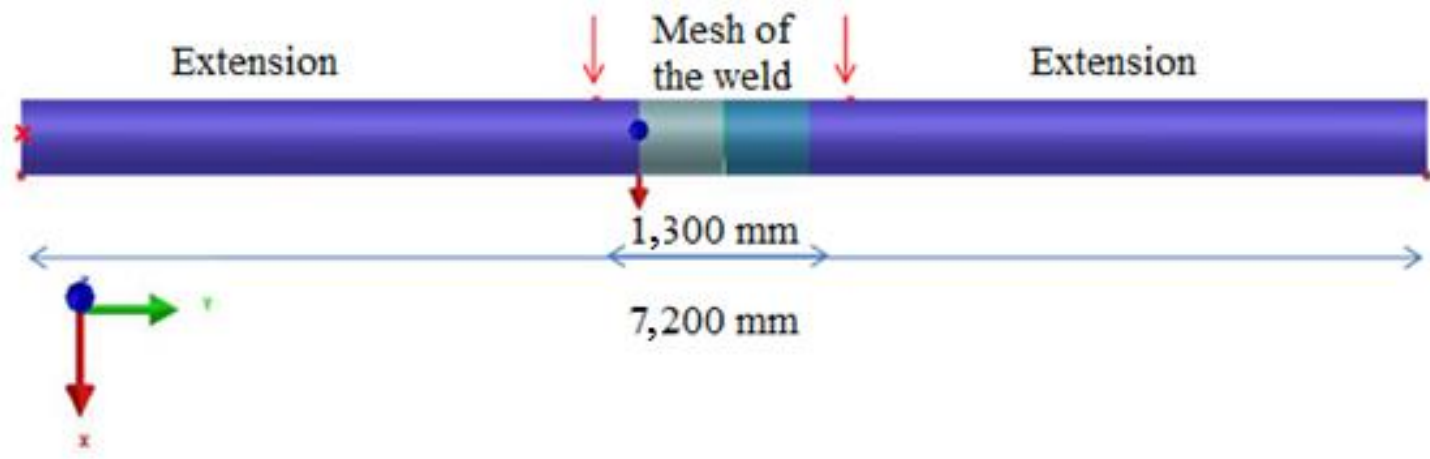

Figure 18: Pipe mesh used in numerical simulations

The boundary conditions are:

- Displacements of internal faces are blocked in the direction of $\vec{u}_{z}$ in order to respect the symmetry; 
- Displacement of the two internal bending points is imposed in the direction of $\vec{u}_{x}$;

- All the displacements of a node are blocked in order to get rid of the rigid body displacements. It is worth nothing that our results are fitting well the beginning of the curve moment of force-CMOD, and the deviation of the crack in the weld and in the 316L material as during the test is correctly represented. However, one can see that these parameters of the GTN model overestimate the strength compared to experimental data, as presented in Figure 19.

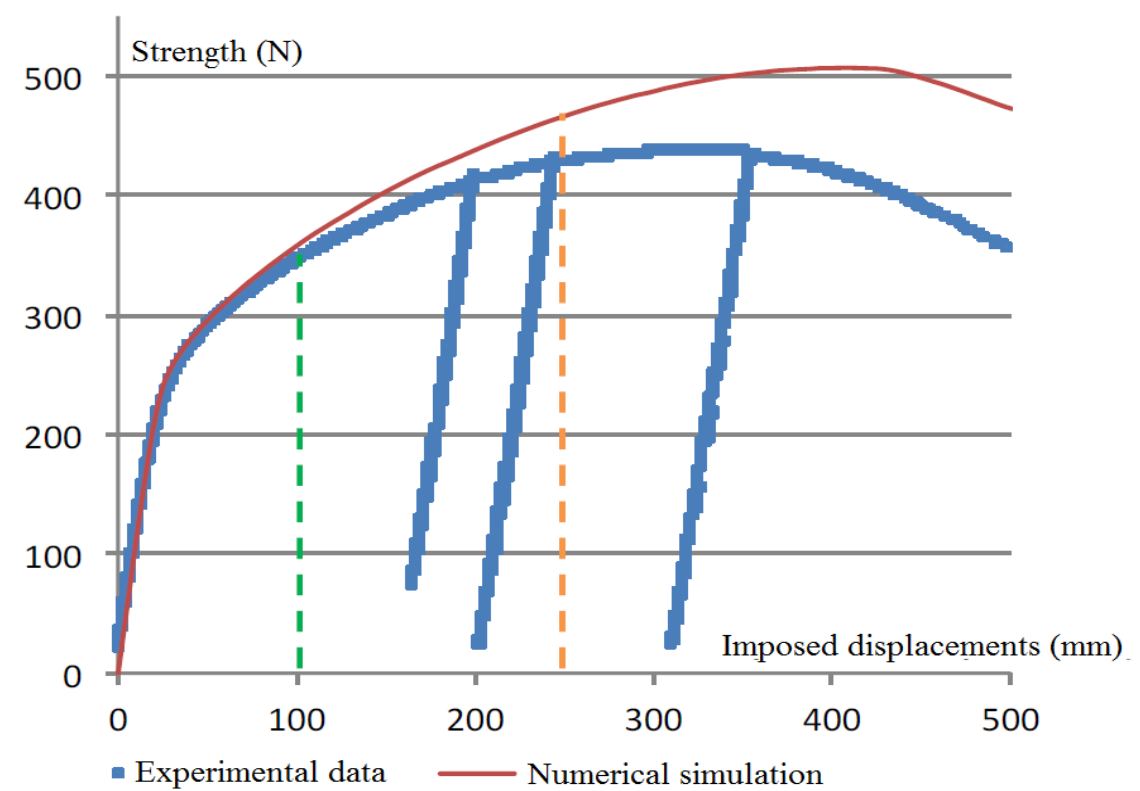

Figure 19: Comparison between experimental data and numerical results for the Pipe: StrengthImposed displacements curve

These results are not satisfactory but can be explained by the lack of experimental data on CT specimens for the stainless steel: the mesh size determined for the weld metal has also been used for the austenitic part without the possibility to validate this assumption.

Therefore, GTN parameters were adapted for the stainless steel in order to have a better fit on the experimental curves, and the new set of parameters is purely arbitrary and is not related to experimental data. Nevertheless, it seems to verify this kind of adjustment is able to help the prediction of the global behavior of the pipe. The new set of parameters is:

\begin{tabular}{|c|c|c|}
\hline & INCONEL & Stainless steel \\
\hline $\boldsymbol{f}_{\mathbf{0}}$ & $10^{-4}$ & $10^{-4}$ \\
\hline $\boldsymbol{f}_{\boldsymbol{c}}$ & $10^{-4}$ & $6 \cdot 10^{-4}$ \\
\hline $\boldsymbol{\delta}$ & 4 & 10.5 \\
\hline $\boldsymbol{q}$ & 1.5 & 1.5 \\
\hline $\boldsymbol{b}$ & - & - \\
\hline
\end{tabular}

Table 4 : New set of parameters for the simulation

Figure 20 and Figure 21 present the results obtained for the new set of parameters given in Table 4 . Crack deviation in $316 \mathrm{~L}$ is still well reproduced, and the model is able to predict correctly the variation of the force during the test. 


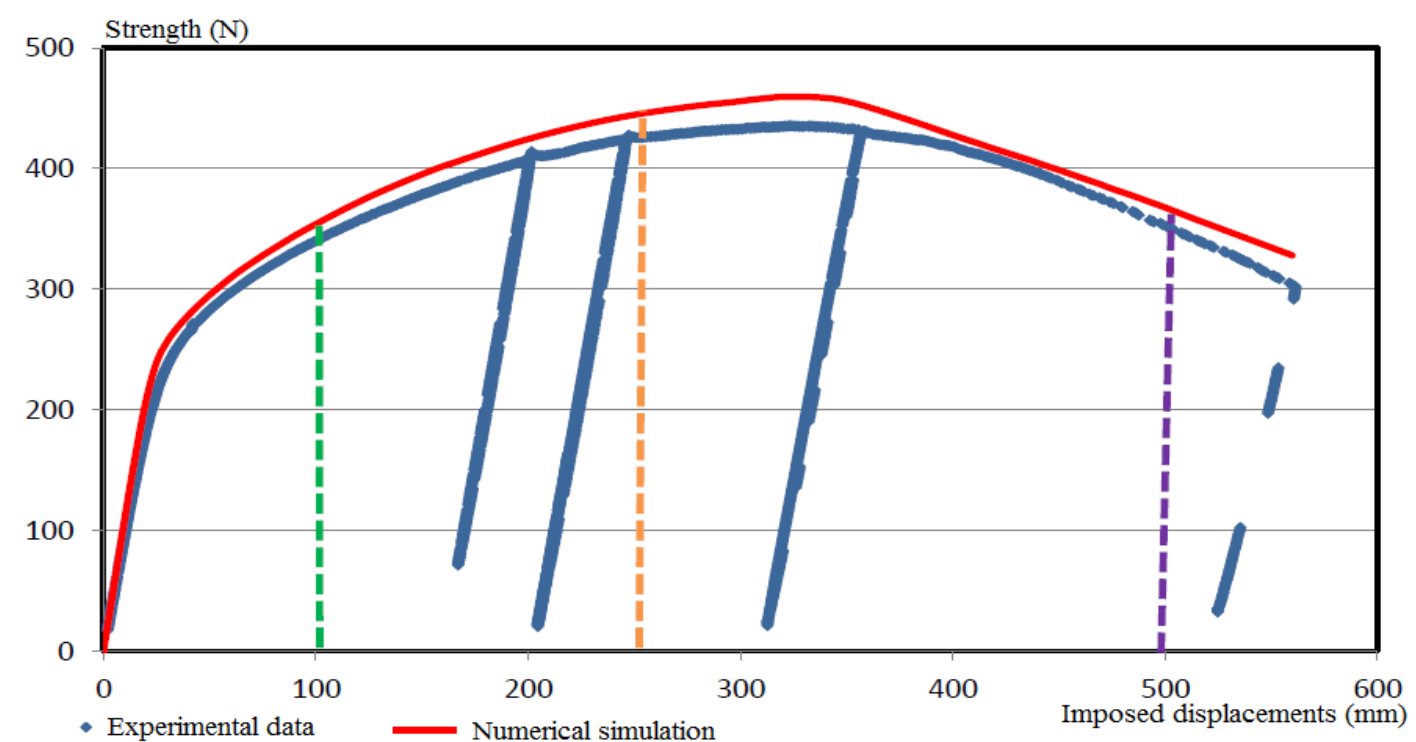

Figure 20: Comparison between experimental data and numerical results for the Pipe: StrengthImposed displacements curve
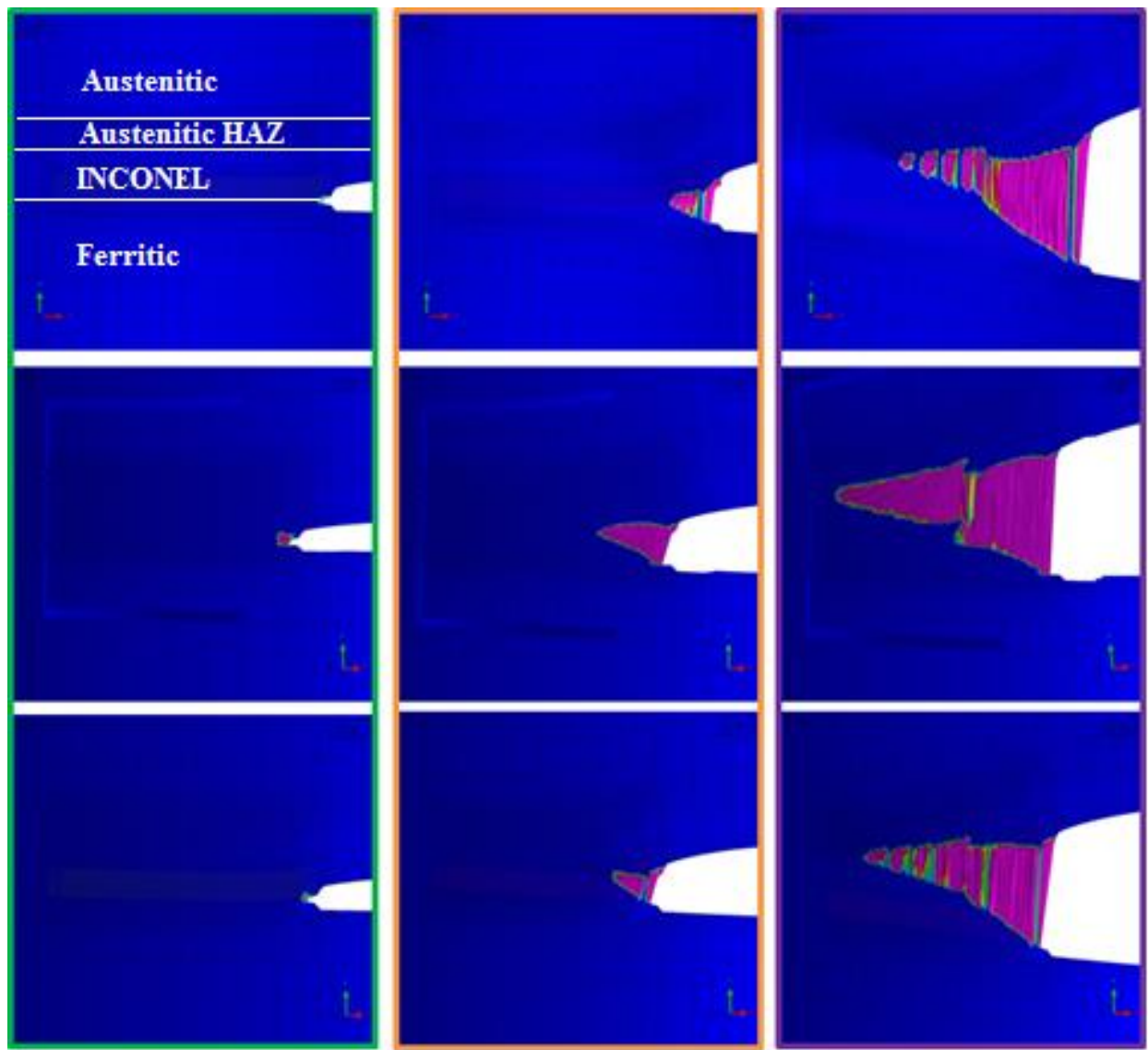

Figure 21: Crack growth in, from top to bottom, the outer skin, the middle thickness and the inner skin for the pipe (green, orange and purple colors are linked to Figure 18) 


\section{CONCLUSION}

This paper presents the whole process to determine GTN parameters, and an application to a real structure test. First, tensile notched tests were used to determine the GTN parameters of the INCONEL and the stainless steel. These parameters were then evaluated with CT specimens, and the results of the simulations fitted well the experimental data.

Then, those parameters were used to perform numerical simulations on a four points bending test using the GTN model, in order to predict the behavior of the crack during the test. The obtained results for the last set of parameters (modified due to the lack of experimental data on austenitic stainless steel) gave a very good agreement between the numerical results and the experimental ones. Indeed, the strength-CMOD curve is well represented, and the behavior of the crack, which propagates inside the INCONEL and continue growing in the austenitic part, like in Figure 1, is also well reproduced. In order to confirm that set of parameters, tests on austenitic CT specimens are necessary.

Finally, it is shown in this paper that the GTN model is able to catch the local mechanical differences between the CT specimens (showing a crack growth parallel to the interface between the INCONEL and the ferritic HAZ) and the large scale pipe responsible of the observed results during the STYLE test.

\section{REFERENCES}

[1] Gurson, Arthur L. "Continuum theory of ductile rupture by void nucleation and growth: Part IYield criteria and flow rules for porous ductile media." Journal of engineering materials and technology 99.1 (1977): 2-15.

[2] Tvergaard, Viggo. "Influence of voids on shear band instabilities under plane strain conditions." International Journal of Fracture 17.4 (1981): 389-407.

[3] Needleman, A., and Tvergaard, V., "An analysis of ductile rupture in notched bars." Journal of the Mechanics and Physics of Solids 32.6 (1984): 461-490.

[4] Leblond, J.B., Perrin, G., and J. Devaux. "Bifurcation effects in ductile metals with nonlocal damage." ASME J. Appl. Mech. (1994): 236-242.

[5] Bourgeois, M., Ancelet, O., Marie, S., and Chapuliot, S. (2012, July). Mechanical characterization for a large test design of a Dissimilar Metals Welding with a narrow gap Nickel alloy weld: experimental and numerical analysis on specimens. In ASME 2012 Pressure Vessels and Piping Conference (pp. 437-444). American Society of Mechanical Engineers.

[6] Bourgeois, M., Chapuliot, S., Marie, S., Ancelet, O., and Kayser, Y. (2014, July). Four points bending test on an EPR type DMW pipe containing a through-wall defect: Experimental and numerical analysis from small specimens until pipe scale. In ASME 2014 Pressure Vessels and Piping Conference (pp. V06AT06A052-V06AT06A052). American Society of Mechanical Engineers.

[SYSTUS] Multiphysics Engineering Simulation Suite: https://www.esi-group.com/fr/solutions$\underline{\text { logicielles/environnement-virtuel/cfd-et-multiphysique/systus }}$ 